\section{Stroke subtypes and factors associated with ischemic stroke in Kinshasa, Central Africa}

\section{Michel Lelo Tshikwela, Fifi Baza Londa, Stéphane Yanda Tongo}

Department of Radiology, Kinshasa University Hospital, Radiology

\section{Abstract}

Background and Purpose: Ischemic stroke causes death and disability worldwide. Better understanding and controlling factors associated will improve the prevention of the disease. This study reviews records of patients with ischemic stroke in Central Africa.

Material and methods: Patients of Bantu ethnicity with clinical diagnosis of stroke and lesion on computed tomography scan from January 2011 to December 2012 were selected. Computed tomographic subtypes of ischemic stroke and factors associated were considered with tropical seasonal variation.

Results: Of the 303 first-ever stroke patients (average age 53 years old, range 3- 84 years old; $62 \%$ male) were included in the study. The prevalence of computed tomography stroke subtypes was: lacunar infarct $(63 \%)$ and non lacunar infarct lesion $(37 \%)$. Silent brin infarct was seen in $9 \%$ of patients. Prevalence of factors associnted with ischemic stroke was:

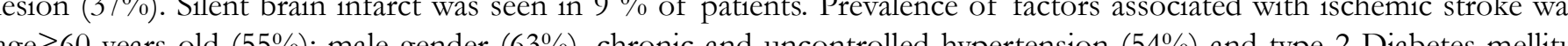
age $\geq 60$ years old $(55 \%)$; male gender $(63 \%)$, chronic and uncontrolled hypertension $(54 \%)$ and type 2 Diabetes mellitus
$(11 \%)$. A seasonal high prevalence was observed in warmer season $(\mathrm{p}<0.05)$. $(11 \%)$. A seasonal high prevalence was observed in warmer season $(\mathrm{p}<0.05)$

Conclusions: This study shows a high prevalence of lacunar infarct than non lacunar in Bantu of Central Africa. Keywords: Ischemic stroke, CT subtypes, Factors associated, Central Africans.

DOI: http://dx.doi.org/10.4314/ahs.v15i1.9

\section{Introduction}

Stroke in sub-Saharan Africa is a major public health an effective global strategy to reduce the risk of preproblem, with higher mortality than in developed coun- mature stroke ${ }^{12}$. With the availability and accessibility tries and occurrence at a younger age $\mathrm{e}^{1-3}$. The rates of the of computed tomography (CT) and diagnostic accuradisease which were considerably lower, are now rapidly cy, tomographic subtypes and factors associated with increasing, even doubling in regions such as rural South ischemic stroke were reviewed in Central Africa.

Africa $^{4-5}$. The reasons for the high burden of stroke are

linked to the high rates of chronic hypertension, type

2 diabetes mellitus (T2DM), excessive alcohol intake,

smoking, insufficient fruit and vegetable consumption

${ }^{6-8}$, sickle cell disease, HIV infection and even antiretroviral drugs?. Also, ischemic stroke is more suffered than hemorrhagic stroke $e^{10,11}$. A large part of Africa as Central Africa was not included in the Interstroke Study phase 1 , and a systematic evaluation of the risk factors

Corresponding author:
Michel Lelo Tshikwela
Department of Radiology,
Kinshasa University Hospital, Radiology
Tel: (+243) 999907216
Email: lelocare60@gmail.com

\section{Materials and methods}

We carried out a retrospective study of black patients who had clinical diagnosis of stroke with sudden onset of neurological deficit (face weakness, arm drift, hemiplegia, aphasia) with CT scan confirmation of ischemic stroke. The study was conducted at two radiology departments of a public and a private hospital in the urban Kinshasa City, Democratic Republic of the Congo (DRC), one of the poorest sub-Saharan country despite its potential of minerals. Patients living in rural areas were not included in this study. The data of the study were collected over a period of two years, between January 2011 and December 2012. The study was approved by the ethics committee of Kinshasa School of Public Health.

The CT examinations were performed within a week of symptoms onset in the usual way cuts $10 \mathrm{~mm}$ spaced $5 \mathrm{~mm}$ without injection of contrast material. Stroke subtypes assessed four OCSP (Oxfordshire Communi- ty Stroke Project Classification) subtypes classification A total of 303 consecutive patients of Bantu ethnic ${ }^{13}$ was used with lacunar circulation infarct (LACI) and group of all ages, regardless of sex were enrolled in the total anterior (TACI), partial anterior (PACI), posterior study.

(POCI) circulation infarcts as non lacunar circulation infarct.

On CT, LACI was seen as a small, round, hypodense lesions of $\leq 25 \mathrm{~mm}$ along the course of penetrating arteries ${ }^{14}$. Non lacunar infarct was defined as a large area of hypodensity involving large vessel in the region of the vascular territory. Patients who suffered from transient ischemic attacks (TIA) defined as symptom resolution within 24 hours of onset and without detectable lesions on CT scan, were not considered. Factors associated with ischemic stroke included: age, gender, chronic arterial hypertension, type 2 diabetes mellitus (T2DM), cigarette smoking, alcohol intake, abdominal obesity. Tropical seasons assessed are a warmer and rainy season (summer) from September 15th to May 14th, with temperatures ranging from 29.4 to $37.8^{\circ} \mathrm{C}$ and high humidity; and a cold season (winter) from May 15th to September 14th with temperatures ranging from 18.3 to $26.7^{\circ} \mathrm{C}$, and low humidity.

Statistical analyzes of the data were performed with the software Epi Info version 6.4 and SPSS for Windows 10 and 16.

\section{Results}

Out of the 303 first-ever ischemic stroke patients, 190 (63\%) developed LACI lesion and 113 (37\%) presented with non-lacunar infarct. Silent brain infarct (SBI) was observed in $9 \%$ of patients. Factors associated with the two subtypes of ischemic stroke were age $\geq 60$ years in 167 patients (55\%), male gender in 190 patients $(63 \%)$, chronic and uncontrolled hypertension was found in 188 patients (62\%), diabetes mellitus in 33 patients $(11 \%)$, hypertension associated with diabetes mellitus in 17 patients (5.6\%), tobacco smoking in 15 patients (5\%), alcohol intake in 22 patients $(7 \%)$ and rainy season involved for 218 patients $(72 \%)$ (Table1)

Table I. Factors associated with subtype of Ischemic infarct

\begin{tabular}{|c|c|c|c|c|}
\hline Factors associated & Lacunar infarct & Non lacunar infarct & Total & $P$-value \\
\hline $\begin{array}{l}\text { Age } \geq 60 \text { years } \\
\text { Male gender } \\
\text { Hypertension } \\
\text { T2DM } \\
\text { Hypertension+T2DM } \\
\text { Smoking status } \\
\text { Alcohol intake } \\
\text { Abdominal obesity }\end{array}$ & $\begin{array}{r}109 \\
153 \\
127 \\
13 \\
8 \\
9 \\
10 \\
0\end{array}$ & $\begin{array}{r}58 \\
47 \\
62 \\
20 \\
9 \\
6 \\
12 \\
2\end{array}$ & $\begin{array}{c}167 / 303(55 \%) \\
200 / 303(63 \%) \\
189 / 303(62 \%) \\
33 / 303(11 \%) \\
17 / 303(5.6 \%) \\
15 / 303(5 \%) \\
22 / 303(7 \%) \\
2 / 303(0.6 \%)\end{array}$ & $\begin{array}{l}0.05 \\
0.07 \\
0.032 \\
0.09\end{array}$ \\
\hline $\begin{array}{l}\text { Raining season } \\
\text { Others }\end{array}$ & $\begin{array}{r}142 \\
12\end{array}$ & $\begin{array}{l}76 \\
14\end{array}$ & $\begin{array}{l}218 / 303(72 \%) \\
26 / 303(8.6 \%)\end{array}$ & 0.05 \\
\hline
\end{tabular}


Apart from history of chronic and uncontrolled hyper- ly active population. This fact may attest that some of tension observed in 127 patients $(67 \%)$ with LACI vs. these stroke lesions may have been silent, pauci-sympin 58 patients $(51 \%)$ with the non lacunar infarct $(\mathrm{p}=$ tomatic, non specific or patients don't seek attention. 0.032), number of multiple ischemic lesions seen in 28 patients with 27 patients $(9 \%)$ having lacunar infarct vs. 1 patient (1\%) with non lacunar infarct, and location in basal ganglia, thalamus and white matter for LACI in 160 patients $(84 \%)$ vs. POCI for non lacunar infarct in 64 patients (57\%), there was no significant difference between the two subtypes of ischemic stroke.

\section{Discussion}

In this study carried out in an urban Central African setting, the CT scan exploration was performed within the week of the abrupt - onset of symptoms. Delays in presentation to CT scan room may be linked to socioeconomic status of the patients. Because of the lack of medical insurance, patients or relatives have to pay the examination even performed in a public hospital. Delayed CT confirmation was also seen by Asefa et al. in Ethiopia ${ }^{14}$. In many low income countries, the relationship between poverty and the level of healthcare has been demonstrated ${ }^{15,16}$. Also in this study, patients suffering from TIA were not included because of the lack of detectable specific lesions based on the CT scan study; modern resonance magnetic imaging showing brain abnormalities as many as in $50 \%$ of patients ${ }^{17}$.

We found that LACI was observed in $63 \%$ of 303 black patients versus $37 \%$ of non lacunar infarct with a significant difference. In USA, several studies have examined the difference in frequency of ischemic stroke subtypes by race. Blacks are more prone to small vessel stroke than Whites ${ }^{18}$. LACI accounts for 20 to $25 \%$ of all ischemic strokes ${ }^{19-21}$, and this proportion is the highest in the African Americans than in the white population ${ }^{22,23}$ In a recent study carry out in 2012, Song et al. ${ }^{24}$ found similar proportion in race distribution of LACI and non LACI stroke using magnetic resonance imaging (MRI) based evaluation including diffusion-weighted-imaging (DWI). Our finding may be attributed to the fact that our patients suffered of chronic hypertension which affect small vessels of the brain.

We found 28 patients $(9 \%)$ with two or more ischemic lesion on CT scan. Obajimi et al found the $9.3 \%$ in 2002 in Ghana ${ }^{25}$. Putaala et a ${ }^{26}$ found $13 \%$ of SBI in 655 MRI-scanned patients aged 15 to 49 with first-ever ischemic stroke. In the Northern Manhattan Study, Willey et $\mathrm{al}^{27}$, found $16 \%$ of SBI in the physical In our study (Thentic and uncontrolled hypertension with all subtype of ischemic stroke. It was noticed in $67 \%$ of cases of LACI vs. $51 \%$ in non lacunar type $(p=0.032)$. It was the most important associated factor found in this study. In Africa, increased rate of hypertension is often attributed to westernization of life tyle and stress of urbanization ${ }^{29}$, and uncontrolle hypertension to the low socioeconomic status.

The T2DM was in $11 \%$ of cases and both in $5.6 \%$ of patients. In the study conducted in Ghana $a^{25}$, the T2DM was an important associated factor and was found in $63 \%$ of cases, while hypertension was found in only $9.1 \%$ of cases studied. These two factors are also found in African Americans ${ }^{22-23}$. Horowitz et colleagues reported that in a cohort of 108 patients with LACI, hypertension was present in $68 \%$, diabetes mellitus in $37 \%$; both occurred in $28 \%$ and neither occurred in $23 \% \%^{30}$. In this central African study, hypertension and associated with these two types of ischemic stroke were age $\geq 60$ years $(55 \%)$, male gender $(63 \%)$ and the rainy, warmer season $(72 \%)$. Age and male gender are known as predisposing factors in the world. The two risk factors most strongly related to a diagnosis of stroke in the study of Hege Ihle-Hansen et al in Norway ${ }^{31}$ were current smoking and hyperlipidemia. In the western part of Africa in Nigeria, Femi et $\mathrm{a}^{32}$ in criminated hypertension and smoking. In this series, we found tobacco smoking habit in $5 \%$ of our patients. Roughly $18 \%$ of strokes are attributable to active cigarette smoking ${ }^{17}$. If increasing alcohol consumption is associated with hemorrhagic stroke, its impact on is chemic stroke has not shown any consistent result ${ }^{17}$. In the current study, heavy alcohol consumption was found in $7 \%$ of patients and cigarette smoking in 5\%, suggesting that these findings cannot be neglected. Data concerning seasonal differences on stroke incidence are conflicting. T2DM both occurred in less than 6\%. Other factor
Little is known about seasonal variability in etiological stroke subtypes in sub- Saharan population. In this research, first-ever ischemic stroke was more common during warmer and raining season $(\mathrm{p}<0.05)$, as reported by Miah et al in Bangladesh ${ }^{33}$ than in winter as seen by Palm and Fares in Europe ${ }^{34,35}$, Diaz in southern hemisphere in Argentina ${ }^{36}$ and Ansa in Nigeria ${ }^{37}$. In our previous stud $y^{38}$ we found that the incidence of ischemic stroke increased in warmed season. Weather conditions could explain the relationship between hematocrit and high morbidity of stroke in warmer season. The relationship between high hematocrit and temperature of the ambient air is typically expressed by dehydration and hemoconcentration due to thermal stress.

in Sub-Saharan Africa the role of infectious diseases with special attention to malaria and other risk factors as waist-to-hip ratio, diet risk score, regular physical activity and lipid profile have to be documented. Stroke studies in rural area need to be undertaken and we presume some difference in the prevalence of stroke in Africans living in rural areas from those of urban cities. This will provide solid epidemiological data for comparative purpose.

Conclusion

This study conducted in Central Africa settings revealed that lacunar stroke subtype is the mostly encountered in Bantu ethnic group. The factors associated with ischemic stroke are described with a seasonal high prevalence observed during the warmer season (summer).

\section{Clinical Implications}

This study has an important clinical implication for our understanding of the causes of stroke in Central Africa. Uncontrolled Hypertension and T2DM have to become the targets of wrestling in black African patients. It is through this strategy in addition with other diverse preventive factors that this burden disease can be reduced. Moreover, this would expand the existing therapeutic options and improve prognosis and outcome of black patients through early detection and treatment of ischemic stroke.

\section{Limitations of the study}

There are some limitations in this study which is a hospital-based, transversal and retrospective one. Many stroke studies are community-based. Only patients who had a brain lesion on CT scan were selected. Many others do not undergo the expensive CT scan exploration because of their low SES. All these biases might have been introduced and might not be the true data of what happened in the community; hence extrapolations to the rest of the community should be done with caution.

Despite these limitations, this study carried out locally in Central Africa and based on CT scan data, seems to be the first one as far as we are aware. It provides valuable information on the pathophysiology of ischemic stroke of black Africans living in urban area which may be useful for black Africans migrated worldwide.

\section{Further research options} Chronic inflammation is believed to be involved in the and rural Tanzania. Adult Morbidity and Mortality. Proepidemiological mechanisms of SBI and LACI $^{39}$ and ject Lancet 2000; 355, 1684-7. 
9. Longo-Mbenza B, LongokoloMashi M, Lelo Tshikwe- 21. Behrouz R., Malek A.R., Torbey M.T. Small Vesla M, Mokondjimobe E, Gombet T, Ellenga-Mbolla B et sel Cerebrovascular Disease: The Past, Present, and al. Relationship between Younger Age, Autoimmunity, Future. Hindawi Publishing Corporation Stroke ReCardiometabolic Risk, Oxidative Stress, HAART, and search and Treatment Volume 2012, Article ID 839151, Ischemic Stroke in Africans with HIV/AIDS. ISRN 8 pages. doi:10.1155/2012/839151

Cardiol. 2011:897908. doi:10.5402/2011/897908. 22. White H, Boden-Albala B, Wang C, Elkind MS, Epub 2011 May 23. 10. Lelo Tshikwela M, Malenga M, Ndoma K, Kabeya type incidence among whites, blacks, and hispanics: K, Longo-Mbenza B. Stroke at Kinshasa city. A CT the Northern Manhattan Study. Circulation 2005; 15; Study. (in french). Panorama médical 1993;4:166-8. 111(10):1327-31.

11.Desalu OO, Wahab KW, Fawale B, Olarenwaju TO, 23. Koch S, Gupta R, McClendon MS, Romano JG. RaBusari OA, Adekoya AO et al. A review of stroke cial-ethnic differences in lacunar infarction in a multiadmissions at a tertiary hospital in rural Southwest- ethnic stroke population. J Stroke Cerebrovasc Dis. ern Nigeria. Ann Afr Med 2011; 10:80-5.

12. O’Donnell MJ, Xavier D, Liu L, Zhang H, Chin 24. Song S, Burgess RE, Kidwell CS. Racial difference by SL, Rao-Melacini P et al. Risk factors for ischaemic and ischemic stroke subtypes: A comprehensive diagnostic intracerebral haemorrhagic stroke in 22 countries (the approach. Hindawi Publishing Corporation Stroke ReINTERSTROKE study): a case-control study. Lancet search and Treatment volume 2012. Article ID 735097, 2010; 376: 112-23.

13. Pittock SJ, Meldrum D, Hardiman O, Thornton J, 25. Obajimi MO, Nyame PK, Jumah KB, Wiredu EK. Brennan P, Moroney JT. The Oxfordshire Community Computed tomographic patterns of intracranial inStroke Project classification: correlation with imaging, farcts in Ghanaians. West African Journal of Medicine associated complications, and prediction of out- 2002,21(2):121-3.

come in acute ischemic stroke. J Stroke Cerebrovasc 26.Putaala J, Haapaniemi E, Kurkinen M, Salonen O, Dis. $2003 ; 12(1): 1-7$

14. Asefa G, Meseret S. CT and clinical correlation of stroke diagnosis, pattern and clinical outcome among stroke patients visting Tikur Anbessa Hospital.

Ethiop Med J. 2010; 48(2):117-22

15. Mukherjee D, Patil CG. Epidemiology and the global burden of stroke. World Neurosurg. 2011; 76(6 Suppl):S85-90.

16. Kleindorfer D, Lindsell C, Alwell KA, Moomaw CJ, 28. Bailey EL, Smith C, Sudlow CL, Wardlaw JM. Woo D, Flaherty ML et al. Patients living in impover- Pathology of lacunar ischemic stroke in humans. ished areas have more severe ischemic strokes. Stroke. A systematic review. Brain Pathol. 2012; 2012; 43(8):2055-9.

17. Ovbiagele B, Nguyen-Huynh MN. Stroke epidemi- 29. Ekezie J, Anyanwu EG, Danborno B, Antony U. ology: advancing our understanding of disease mecha- Impact of urbanization on obesity, anthropometric nism and therapy. Neurotherapeutics 2011; 8 (3), 319- profile and blood pressure in the Igbos of Nigeria.

18. Potter GM, Marlborough F J., Wardlaw JM. Wide 30. Horowitz DR., Tuhrim S, Weinberger JM, Rudolph Variation in Definition, Detection, and Description of SH. Mechanisms in lacunar infarction. Stroke 1999; 23 Lacunar Lesions on Imaging.Stroke 2011; 42: 359- 66. (3), 325-7.

19. Bamford J, Sandercock P, Jones L, Warlow P. The 31. Ihle-Hansen H, Thommessen B, Wyller TB, natural history of lacunar infarction: the Oxfordshire Engedal K, Fure B. Risk factors for and incidence Community Stroke Project. Stroke. 1997; 18:545-51. of subtypes of ischemic stroke. Funct Neurol. 2012; 20. Sacco S, Marini C, Totaro R, Russo T, Cero- 27(1):35-40.

ne D, Carolei A. A population-based study of the 32. Femi OL, Mansur N. Factors associated with death incidence and prognosis of lacunar stroke. Neurology and predictors of one- month mortality from stroke in 2006; 66(9), 1335-8.
2013;4, Suppl S1:56-61.

33. Miah AH, Sutradhar SR, Ahmed S, Bhattacharjee M, Alam MK, Bari MA et al. Seasonal variation in type of stroke and its common risk factors. Mymensingh Med J. 2012; 21(1):13-20.

May 19. [Epub ahead of print]

34. Palm F, Santos MD, Urbanek C, Greulich M, Zimmer K, Safer A et al. Stroke seasonality associations with subtype, etiology and laboratory results in the Ludwigshafen Stroke Study (LuSSt). Eur J Epidemiol. 2013 Feb 6. [Epub ahead of print]

35. Fares A. Winter cardiovascular diseases phenomenon. North Am J Med Sci 2013; 5:266-79.

36. Díz A, Gerschcovich ER, Díz AA, Antí F, Gonorazky S.Seas Hospitalizations and Mortality in a South American Community Hospital. J Stroke Cerebrovasc Dis. 2012
37. Ansa VO, Ekott JU, Essien IO, Bassey EO. Seasonal variation in admission for heart failure, hypertension and stroke in Uyo, South Eastern Nigeria. Ann Afr Med. 2008; 7(2):62-6.

38. Longo-Mbenza B, Phanzu-Mbete LB, M'Buyamba-Kabangu JR, Tonduangu K, Mvunzu M, Muvova Det al. Hematocrit and stroke in black Africans under tropical climate and meteorological influence. Ann Med Interne (Paris). 1999; 150(3):171-7;

39. Sarchielli P, Nardi K, Chiasserini D, Eusebi P, Tantucci M, Di Piero $V$ et al. Immunological profile of silent br 2013; 8(7):e68428. doi: 10.1371/journal.pone.0068428 Print 2013. 